\title{
Supporting Information \\ Highly selective indole oxidation catalyzed by a Mn-containing artificial mini-enzyme
}

\author{
Linda Leone ${ }^{\mathrm{a}}$, Daniele D’Alonzo ${ }^{\mathrm{a}}$, Ornella Maglio ${ }^{\mathrm{a}, \mathrm{b}}$, Vincenzo Pavone ${ }^{\mathrm{a}}$, \\ Flavia Nastri ${ }^{\mathrm{a},{ }^{*}}$ and Angela Lombardi ${ }^{\mathrm{a}, *}$
}

\begin{abstract}
${ }^{a}$ Department of Chemical Sciences, University of Napoli “Federico II," Via Cintia 21, Napoli 80126, Italy
${ }^{\mathrm{b}}$ Institute of Biostructures and Bioimages-National Research Council, Via Mezzocannone 16, Napoli 80134, Italy

*Correspondence to Angela Lombardi email: alombard@unina.it; Flavia Nastria email: flavia.nastri@unina.it
\end{abstract}

\section{Table of contents}

Figure S1. UV-Vis and high resolution ESI-MS spectra of the major product detected upon indole oxidation at $\mathrm{pH} 8.5$.

Figure S2. ${ }^{1} \mathrm{H}$ NMR spectrum of pure isolated 2-TFE-3-oxindole.

Figure S3. ${ }^{13} \mathrm{C}$ NMR spectrum of pure isolated 2-TFE-3-oxindole.

Figure S4. ${ }^{19} \mathrm{~F}$ NMR spectrum of pure isolated 2-TFE-3-oxindole.

Figure S5. ${ }^{1} \mathrm{H}-{ }^{13} \mathrm{C}$ HMBC spectrum of pure isolated 2-TFE-3-oxindole.

Figure S6. EI-MS spectrum of pure isolated 2-TFE-3-oxindole, acquired by GC-MS analysis.

Figure S7. RP-HPLC chromatograms of indole oxidation catalyzed by Mn-MC6*a at pH 8.5 acquired after 15 and 60 minutes of reaction.

Figure S8. UV-Vis and high resolution ESI-MS spectra of indole-2,3-dione.

Table S1. Identified products obtained upon indole oxidation by Mn-MC6*a in the explored reaction conditions.

Figure S9. Superimposition of analytical RP-HPLC chromatograms of purified 2-TFE-3-oxindole acquired soon after its purification and after $12 \mathrm{~h}$ in $\mathrm{H}_{2} \mathrm{O}$.

Figure S10. Comparison of the ${ }^{1} \mathrm{H}$ NMR spectra of 2-TFE-3-oxindole acquired before and after $12 \mathrm{~h}$ in $\mathrm{D}_{2} \mathrm{O}$.

Figure S11. EI-MS spectrum of pure 2-hydroxy-3-oxindole, acquired by GC-MS analysis after reaction of 2TFE-3-oxindole with water.

Figure S12. RP-HPLC chromatograms of indole oxidation catalyzed by Mn-MC6*a at pH 10.5.

Figure S13. RP-HPLC chromatogram of indole oxidation catalyzed by Mn-MC6*a at pH 6.5.

Figure S14. UV-Vis absorption and high-resolution ESI-MS spectra of the products observed upon indole oxidation by Mn-MC6*a at $\mathrm{pH} 6.5$. 
Figure S15. RP-HPLC chromatogram of indole oxidation catalyzed by Mn-MC6*a at $\mathrm{pH} 8.5$ in the presence of $40 \% v / v$ methanol.

Figure S16. EI-MS spectrum of 2-methoxy-3-oxindole, acquired by GC-MS analysis.

Figure S17. RP-HPLC chromatogram of indole oxidation catalyzed by Mn-MC6*a at $\mathrm{pH} 8.5$ in the presence of $40 \% v / v$ ethanol.

Figure S18. EI-MS spectrum of 2-ethoxy-3-oxindole, acquired by GC-MS analysis.

Figure S19. RP-HPLC chromatogram of indole oxidation catalyzed by Mn-MC6*a at pH 8.5 in the absence of co-solvents.

Figure S20. Superimposition of far UV region CD spectra of Mn-MC6*a $(10 \mu \mathrm{M})$ acquired in $5 \mathrm{mM}$ sodium phosphate $\mathrm{pH} 8.5$ and in the presence of different co-solvents.

Table S2. Far-UV region CD parameters for Mn-MC6*a in aqueous solution at pH 8.5 with different cosolvents.

Figure S21. RP-HPLC chromatogram of indole oxidation catalyzed by Mn-MC6*a at $\mathrm{pH} 8.5$ in the absence of $\mathrm{O}_{2}$.

Figure S22. RP-HPLC chromatogram of $N$-methyl-indole oxidation catalyzed by Mn-MC6*a at pH 8.5.

Figure S23. RP-HPLC chromatograms of $N$-acetyl-indole oxidation in the presence of Mn-MC6*a at pH 8.5.

Figure S24. High resolution ESI-MS spectrum of $\mathrm{N}$-methyl-2-oxindole, observed in isotopic-labelling experiments with $\mathrm{H}_{2}{ }^{18} \mathrm{O}_{2}$ as oxidant and Mn-MC6*a as catalyst.

Figure S25. EI-MS spectra of 2-TFE-3-oxindole ${ }^{18} \mathrm{O}$ label exchange with the $\mathrm{H}_{2}{ }^{18} \mathrm{O}$.

Figure S26. Comparison of HPLC chromatograms of indole oxidation catalyzed by Mn-MC6*a at pH 8.5 in the absence and in the presence of D-mannitol as $\mathrm{OH}$ radical scavenger.

Figure S27. Calibration curves obtained by RP-HPLC analysis of 2-TFE-3-oxindole, isatin and indole solutions at known concentration.

Figure S28. Superimposition of RP-HPLC chromatograms of indole oxidation catalyzed by Mn-MC6*a at pH 8.5 before and after extraction with ethyl acetate and reconstitution in $\mathrm{H}_{2} \mathrm{O}$. 

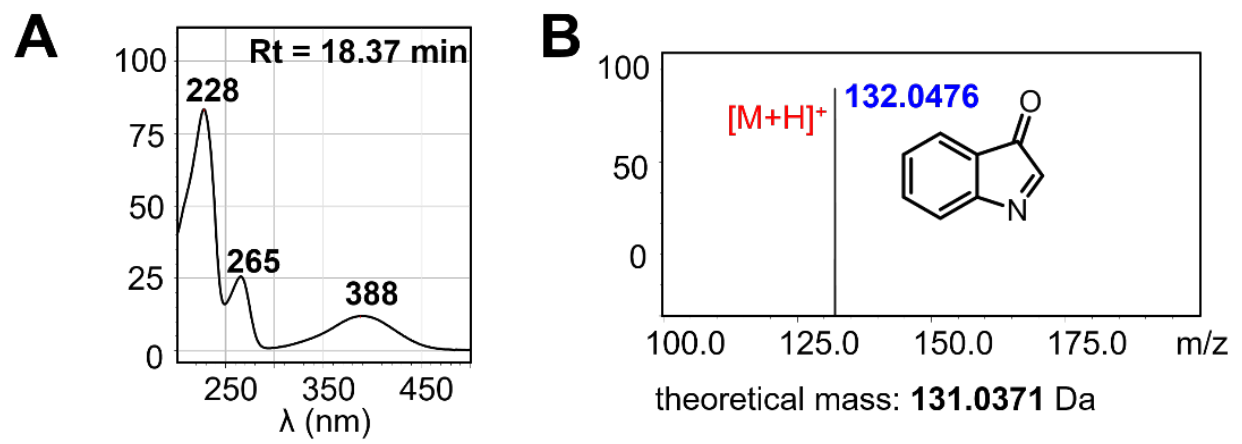

Figure S1. (A) UV-Vis spectrum and (B) high resolution ESI-MS spectrum of the major product detected upon indole oxidation at $\mathrm{pH} 8.5$ and in the presence of TFE $(40 \% \mathrm{v} / \mathrm{v})$. Data were consistent with those reported for 3-oxindolenine [ref. 37 of the manuscript]. Molecular structure of 3-oxindolenine is also shown. 
A

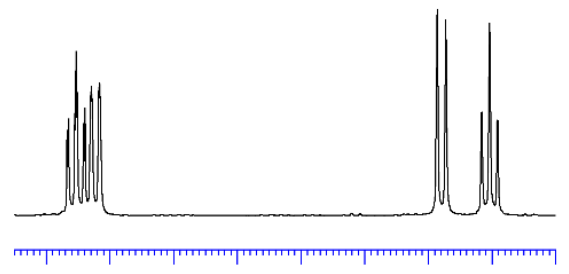

$\begin{array}{llllllll}7.6 & 7.5 & 7.4 & 7.3 & 7.2 & 7.1 & 7.0 & \text { ppm }\end{array}$

C

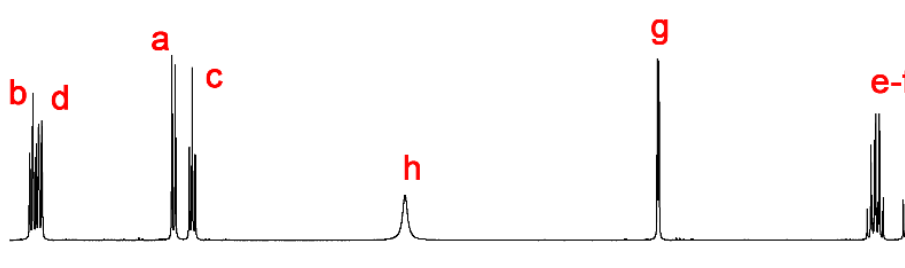

B

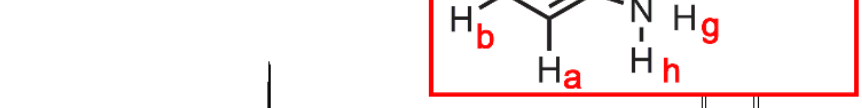

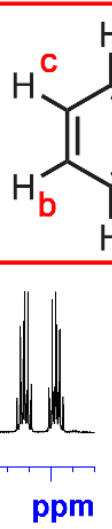

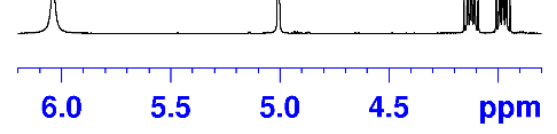

\begin{tabular}{|c|c|c|c|c|c|c|c|c|c|c|c|c|}
\hline 1 & 11 & 1 & 1 & -0 & 1 & 1 & 1 & 1 & 1 & 1 & & \\
\hline & 7.0 & 6.5 & 6.0 & 5.5 & 5.0 & 4.5 & 4.0 & 3.5 & 3.0 & 2.5 & 2.0 & ppm \\
\hline
\end{tabular}

Figure S2. ${ }^{1} \mathrm{H}$ NMR spectrum of pure isolated 2-TFE-3-oxindole, acquired in acetonitrile d3. The inset (red contour) shows the proposed molecular structure, with protons labelled with red letters. (A) Detail of the $7.65-6.80 \mathrm{ppm}$ region; (B) detail of the $6.20-3.80$ ppm region; (C) full spectrum. In panel (C), peaks are labelled as the corresponding protons in the inset.

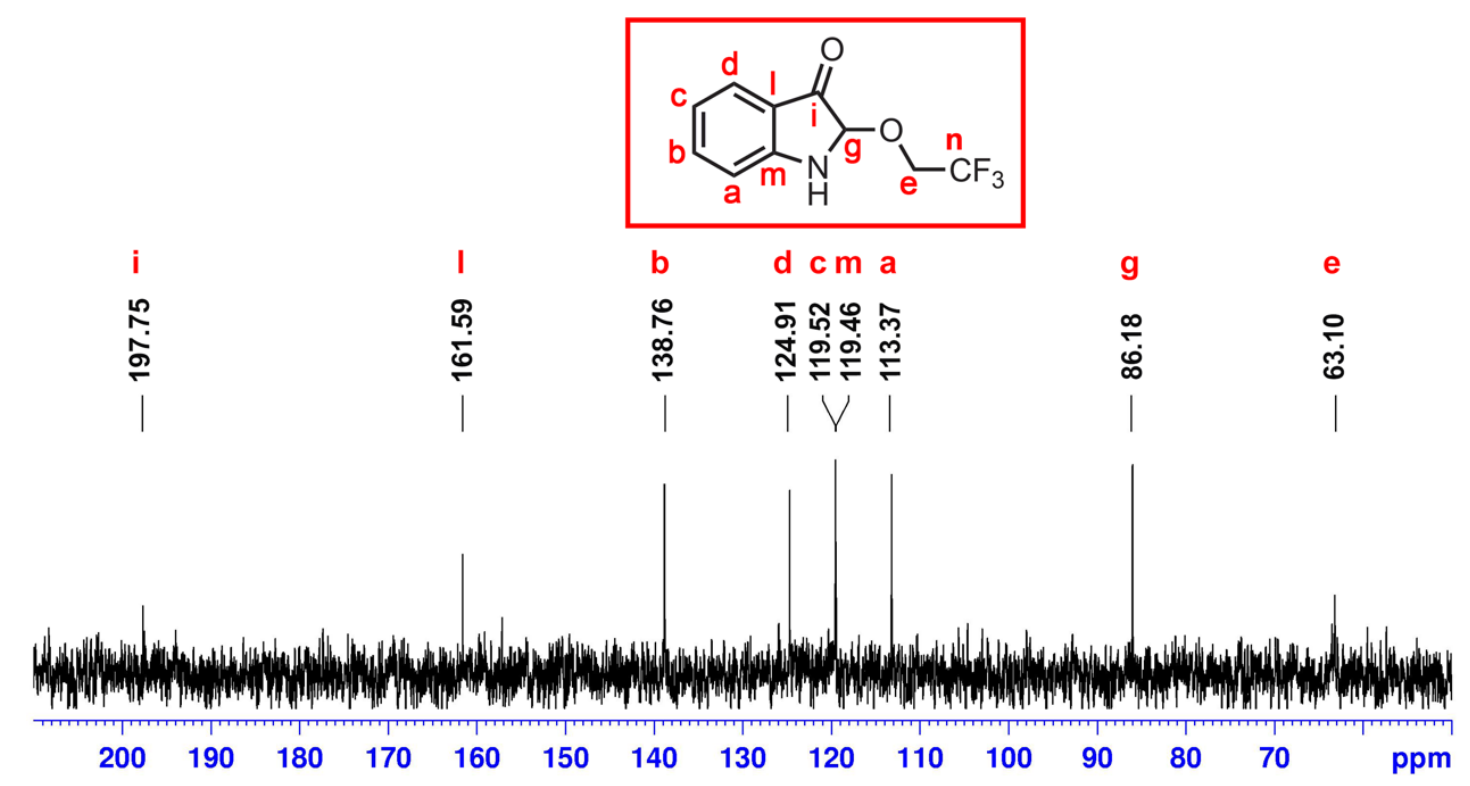

Figure S3. ${ }^{13} \mathrm{C}$ NMR spectrum of pure isolated 2-TFE-3-oxindole, acquired in dimethylsulfoxide d6. The inset (red contour) shows the proposed molecular structure, with carbons labelled with red letters. 


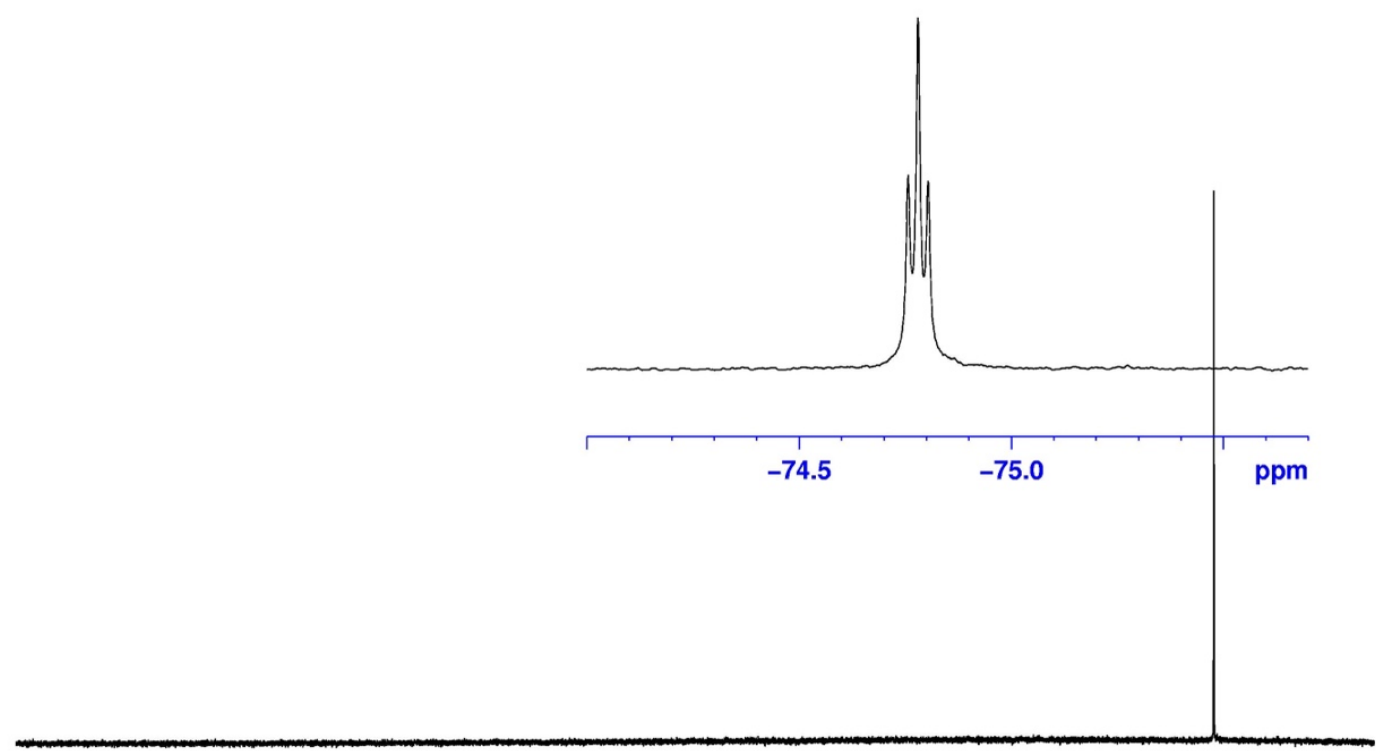

$\begin{array}{lllllllllllllllllll}90 & 80 & 70 & 60 & 50 & 40 & 30 & 20 & 10 & 0 & -10 & -20 & -30 & -40 & -50 & -60 & -70 & -80 & \mathrm{ppm}\end{array}$

Figure S4. ${ }^{19} \mathrm{~F}$ NMR spectrum of pure isolated 2-TFE-3-oxindole, acquired in dimethylsulfoxide $\mathrm{d}_{6}$.

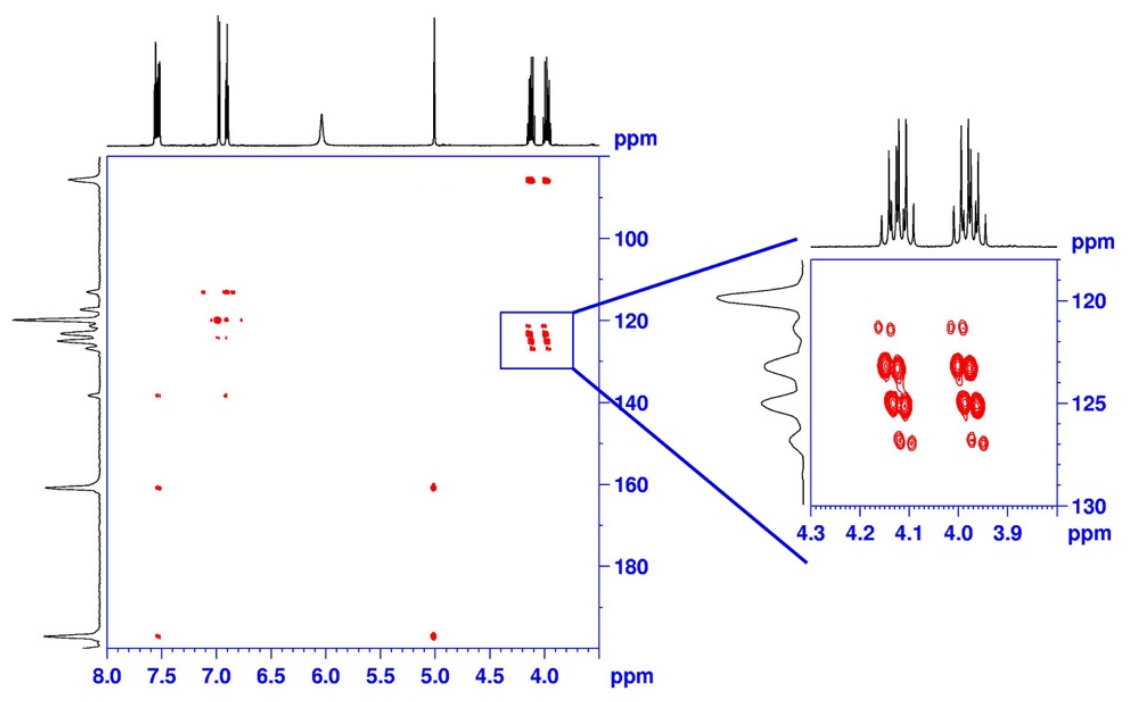

Figure S5. ${ }^{1} \mathrm{H}-{ }^{13} \mathrm{C}$ HMBC spectrum of pure isolated 2-TFE-3-oxindole, acquired in dimethylsulfoxide d6.

${ }^{1} \mathrm{H}$ NMR (acetonitrile d3): $\delta 7.56(\mathrm{H}-\mathrm{b}, \mathrm{ddd}, \mathrm{J}=8.3 \mathrm{~Hz}, 7.0 \mathrm{~Hz}, 1.3 \mathrm{~Hz}) ; \delta 7.53(\mathrm{H}-\mathrm{d}, \mathrm{ddd}, \mathrm{J}=7.8 \mathrm{~Hz}, 1.3 \mathrm{~Hz}, 0.7 \mathrm{~Hz}) ; \delta$ $6.98(\mathrm{H}-\mathrm{a}, \mathrm{dd}, \mathrm{J}=8.3 \mathrm{~Hz}, 0.7 \mathrm{~Hz}$ ); $\delta 6.91$ (H-c, ddd, J = 7.8 Hz, 7.0 Hz, $0.8 \mathrm{~Hz}) ; \delta 6.00(\mathrm{H}-\mathrm{h}, \mathrm{s}(\mathrm{br})$ ); $\delta 5.01$ (H-g, d, J = $3.8 \mathrm{~Hz}$ ); $\delta$ 4.12-3.97 (H-e/f, dq, J = $18.8 \mathrm{~Hz}, 9.0 \mathrm{~Hz}$ ).

${ }^{13} \mathrm{C}$ NMR (dimethylsulfoxide d6): $\delta 197.75(\mathrm{C}-\mathrm{i}) ; \delta 161.59(\mathrm{C}-1) ; \delta 138.76(\mathrm{C}-\mathrm{b}) ; \delta 124.91(\mathrm{C}-\mathrm{d}) ; \delta 124.22\left(\mathrm{C}-\mathrm{n}, \mathrm{q},{ }^{1} \mathrm{~J}_{\mathrm{C}-\mathrm{F}}\right.$ $=271 \mathrm{~Hz})^{*} ; \quad \delta \quad 119.52 \quad(\mathrm{C}-\mathrm{c}) ; \quad \delta \quad 119.46 \quad(\mathrm{C}-\mathrm{m}) ; \quad \delta \quad 113.37 \quad(\mathrm{C}-\mathrm{a}) ; \quad \delta \quad 86.18 \quad(\mathrm{C}-\mathrm{g}) ; \quad \delta \quad 63.10 \quad(\mathrm{C}-\mathrm{e}) ;$ *derived from ${ }^{1} \mathrm{H}-{ }^{13} \mathrm{C}$ HMBC analysis.

${ }^{19} \mathrm{~F}$ NMR (acetonitrile d3): $\delta-74.78(\mathrm{t}, \mathrm{J}=9.0 \mathrm{~Hz})$. 


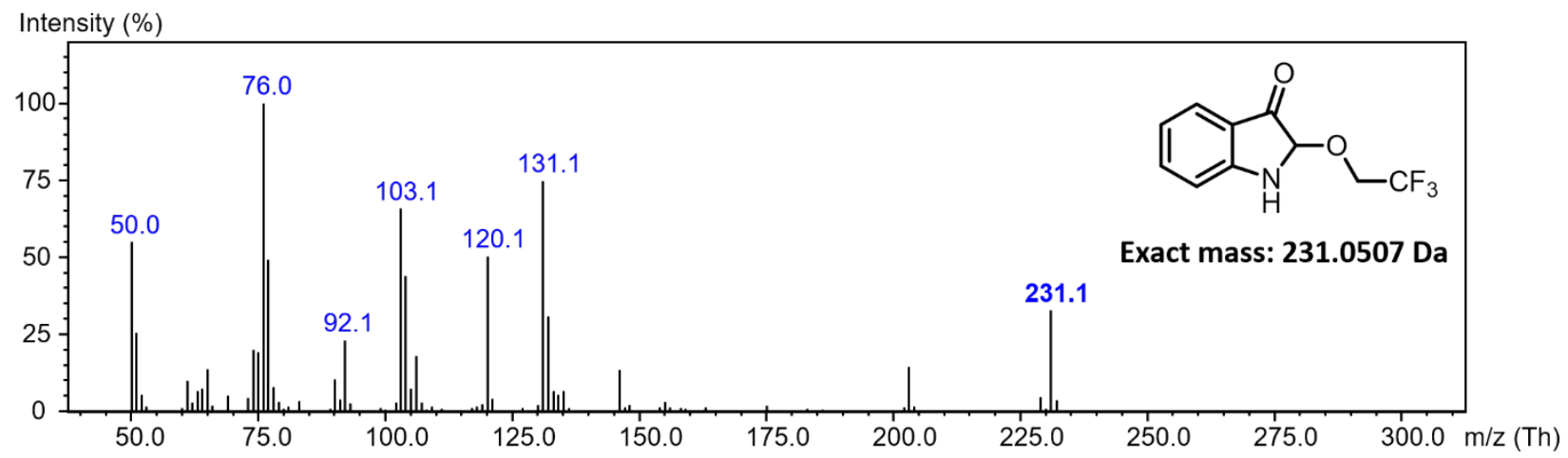

Figure S6. EI-MS spectrum of pure isolated 2-TFE-3-oxindole, collected upon GC-MS analysis of the pure compound dissolved in ethyl acetate.
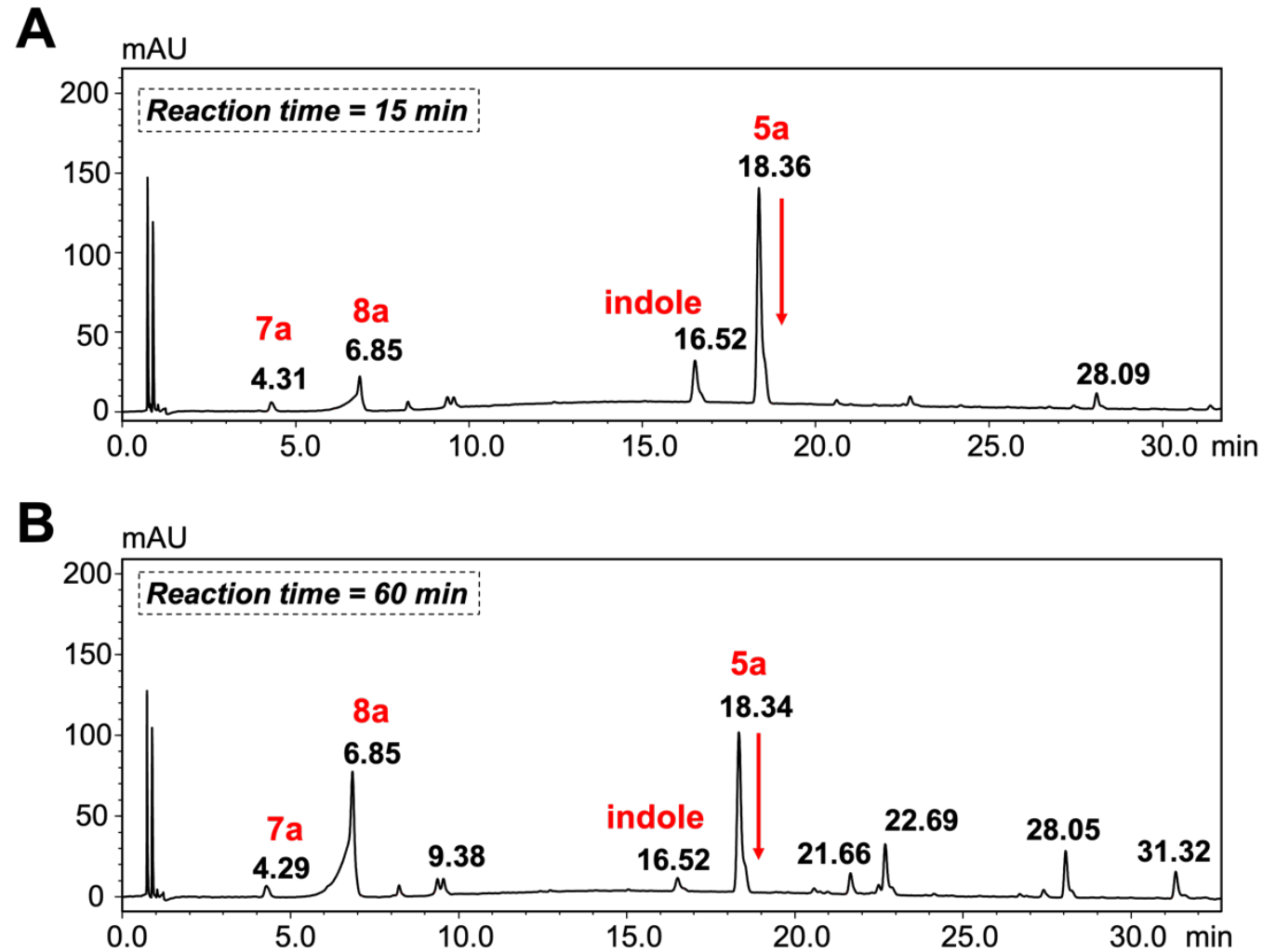

Figure S7. RP-HPLC chromatograms at $\lambda=240 \mathrm{~nm}$ of indole oxidation catalyzed by Mn-MC6*a at $\mathrm{pH} 8.5$ and in the presence of $40 \% v / v$ TFE. Traces acquired after (A) 15 and (B) 60 minutes after addition of $\mathrm{H}_{2} \mathrm{O}_{2}$. Identified products are labelled according to Scheme 3 (main text). 


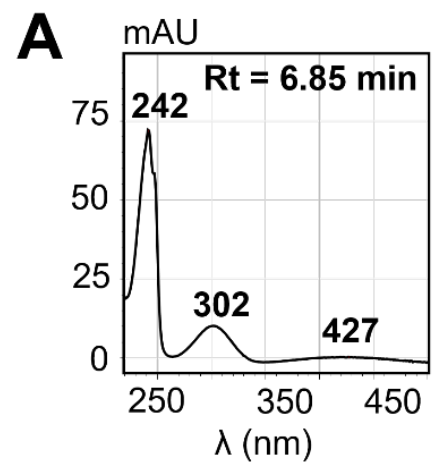

B

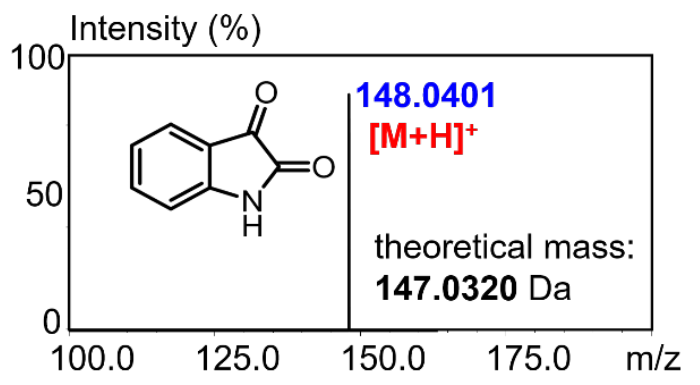

Figure S8. UV-Vis (A) and high-resolution mass spectrum (B) of the product eluted at 6.85 min, which was identified as indole-2,3-dione (isatin). Molecular structure and theoretical mass of the product are also shown. 
Table S1. Identified products observed upon indole oxidation by Mn-MC6*a in the presence of TFE $(40 \% v / v)$ and in different $\mathrm{pH}$ conditions.

\begin{tabular}{|c|c|c|c|c|c|}
\hline $\begin{array}{l}\text { Retention } \\
\text { time (min) }\end{array}$ & $\lambda_{\max }(\mathrm{nm})$ & $\begin{array}{c}\text { Experimental } \\
\text { mass (Da) }\end{array}$ & $\begin{array}{l}\text { Theoretical } \\
\text { mass (Da) }\end{array}$ & Compound & notes \\
\hline 4.1 & $226,265,385$ & $\begin{array}{c}131.0398^{[\mathrm{a}]} \\
149.1^{[\mathrm{b}]}\end{array}$ & 149.0477 & $\begin{array}{l}\text { 2-hydroxy-3- } \\
\text { oxindole }\end{array}$ & $\begin{array}{c}\text { observed at } \mathrm{pH} \\
6.5\end{array}$ \\
\hline 6.8 & $\begin{array}{c}242,303 \\
428(\mathrm{w})\end{array}$ & 147.0323 & 147.0320 & $\begin{array}{l}\text { Indole-2,3-dione } \\
\text { (isatin) }\end{array}$ & $\begin{array}{l}\text { predominant at } \\
\mathrm{pH}>8.5\end{array}$ \\
\hline 8.2 & $247,275(\mathrm{sh})$ & 133.0530 & 133.0528 & 2-oxindole & traces \\
\hline 9.5 & $215,249,300$ & 149.0481 & 149.0477 & $\begin{array}{l}N \text {-formyl-amino- } \\
\text { benzaldehyde }\end{array}$ & $\begin{array}{c}\text { formed at } \mathrm{pH}> \\
8.5\end{array}$ \\
\hline 18.3 & $228,265,388$ & $\begin{array}{c}131.0378^{[\mathrm{a}]} \\
231.1^{\mathrm{b}]}\end{array}$ & 231.0507 & 2-TFE-3-oxindole & $\begin{array}{l}\text { Predominant at } \\
\mathrm{pH} 7.5,8.5\end{array}$ \\
\hline 20.1 & $214,258,405$ & 246.0785 & 246.0793 & $\begin{array}{c}\text { 2-(3-indolyl)-3- } \\
\text { oxindolenine (dimer) }\end{array}$ & $\begin{array}{c}\text { Detected at } \mathrm{pH} \\
6.5\end{array}$ \\
\hline 27.0 & $\begin{array}{c}224,259(\mathrm{sh}) \\
279,398(\mathrm{w})\end{array}$ & 363.1392 & 363.1372 & $\begin{array}{l}\text { 2,2-bis(3-indolyl)-3- } \\
\text { oxindole (trimer) }\end{array}$ & $\begin{array}{l}\text { predominant at } \\
\text { pH } 6.5\end{array}$ \\
\hline \multicolumn{6}{|c|}{$\begin{array}{l}{ }^{[a]} \text { determined by ESI-MS; }{ }^{[b]} \text { determined by GC-EI-MS. The difference between experimental ESI and EI mass values } \\
\text { was attributed to loss of } \mathrm{H}_{2} \mathrm{O}(-18.1 \mathrm{Da}) \text { or TFE }(-100.1 \mathrm{Da}) \text { during the ESI-MS analysis for 2-hydroxy-3-oxindole and } \\
\text { 2-TFE-3-oxindole, respectively. } \\
\text { w = weak; sh = shoulder. } \\
\text { Additional unidentified products have not been included. }\end{array}$} \\
\hline
\end{tabular}



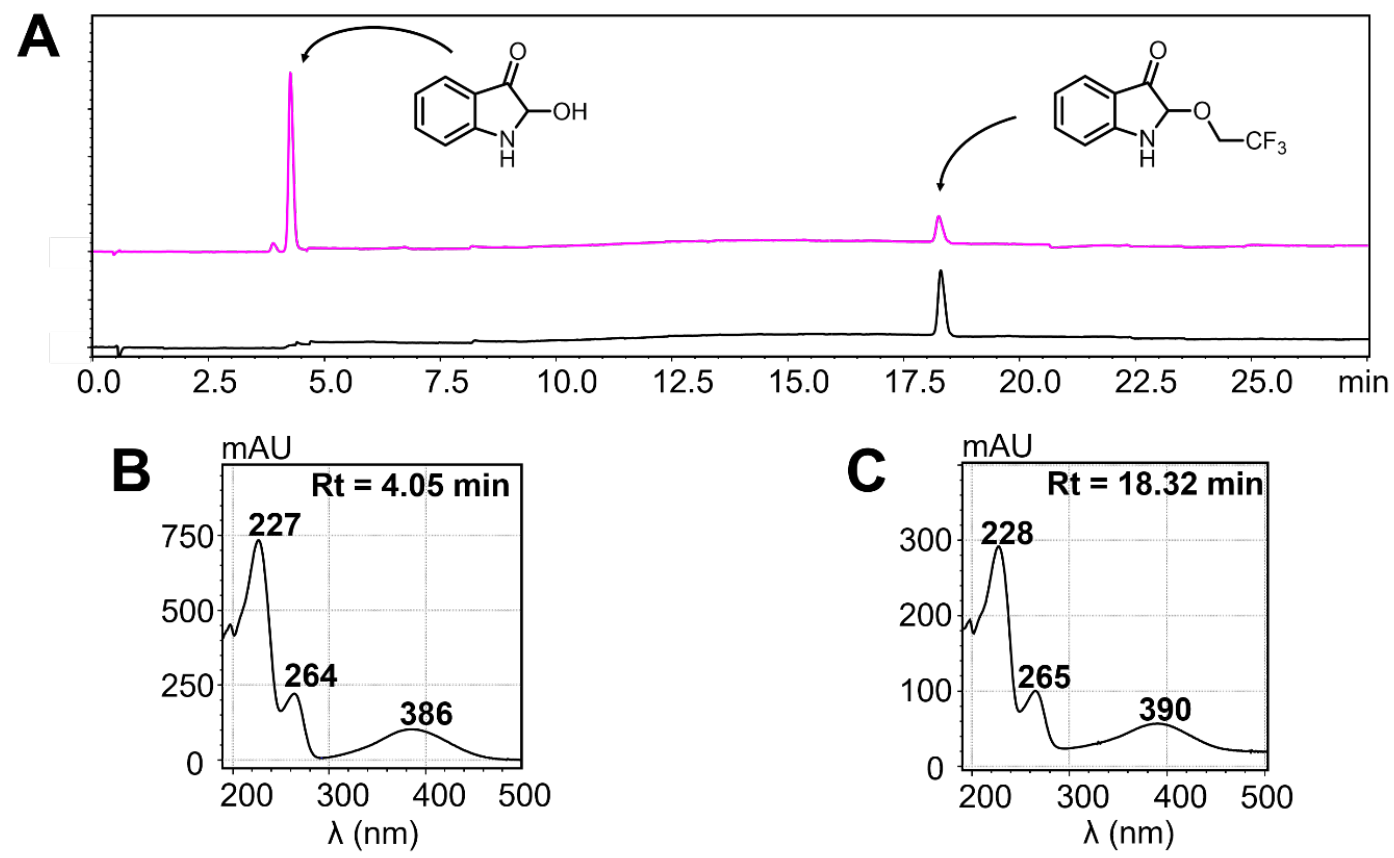

Figure S9: (A) Superimposition of analytical RP-HPLC chromatograms at $\lambda=240 \mathrm{~nm}$ of purified 2-TFE-3-oxindole acquired soon after its purification (black trace) and after $12 \mathrm{~h} \mathrm{in} \mathrm{H}_{2} \mathrm{O}$ (magenta trace). UV-Vis absorption spectra of the products eluted at: (B) $4.57 \mathrm{~min}$ and (C) $18.47 \mathrm{~min}$

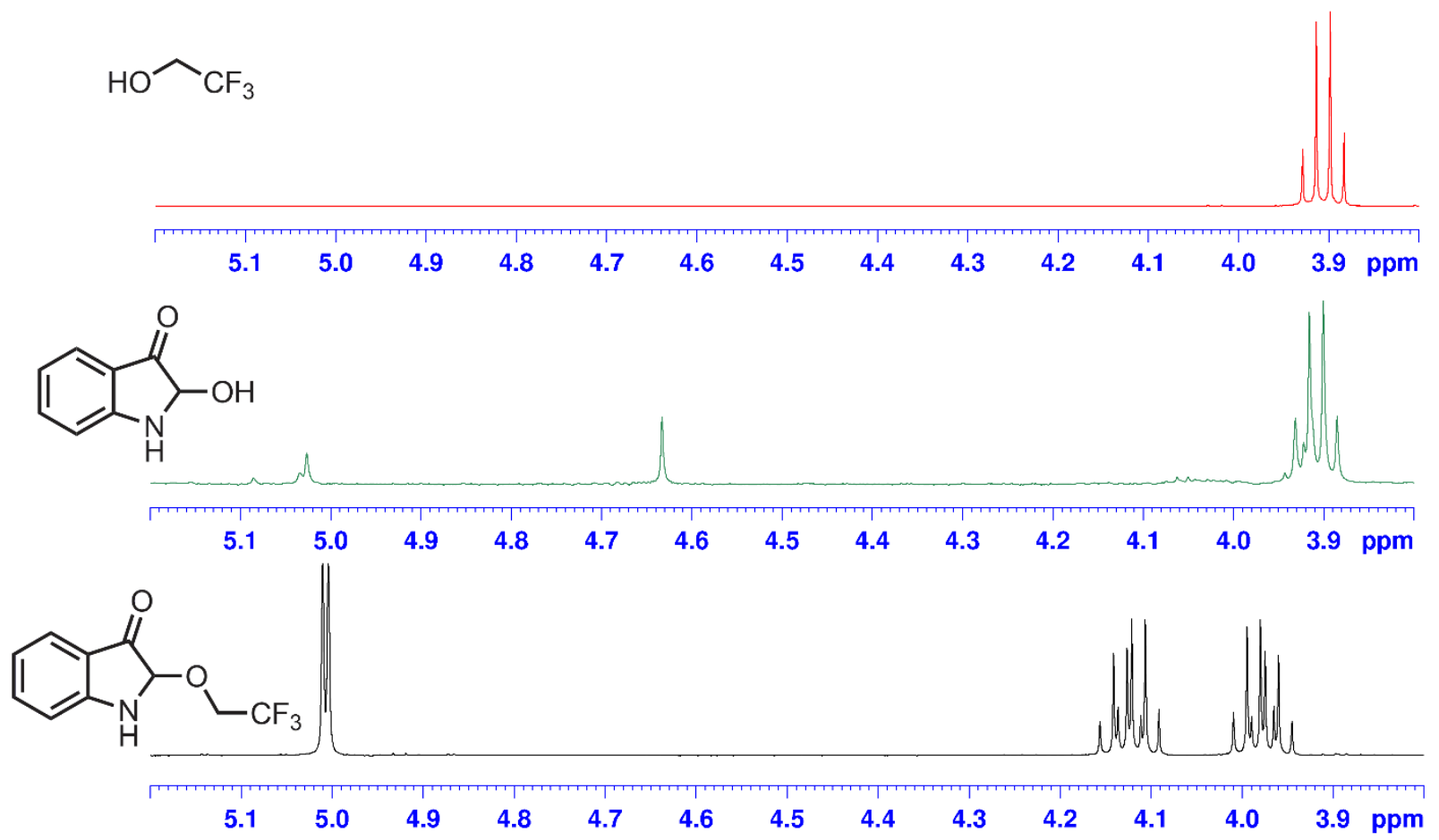

Figure S10. Comparison of ${ }^{1} \mathrm{H}$ NMR spectra, in the $5.2-3.8 \mathrm{ppm}$ region, of: 2-TFE-3-oxindole in acetonitrile d3 (black trace); 2-hydroxy-3-oxindole, produced from 2-TFE-3-oxindole after $12 \mathrm{~h}$ in $\mathrm{D}_{2} \mathrm{O}$ :acetonitrile d3 9:1 ( $v / v$ ) (green trace); TFE in $\mathrm{D}_{2} \mathrm{O}$ :acetonitrile $\mathrm{d}_{3}$ 9:1 ( $\left.v / v\right)$ (red trace). The disappearance of the signals of ligated TFE (double quartets at $3.97 \mathrm{ppm}$ and $4.12 \mathrm{ppm}$ ) and the presence of the signal of unbound TFE (quartet at $3.90 \mathrm{ppm}$ ) indicates the conversion of 2-TFE-3-oxindole into 2-hydroxy-3-oxindole. 


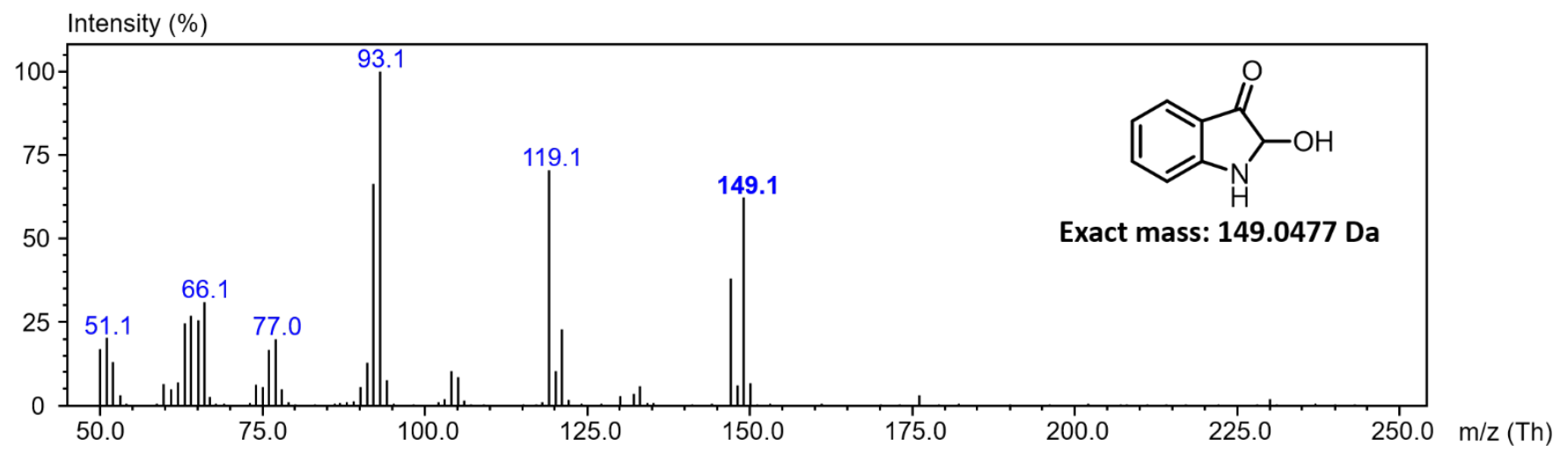

Figure S11. EI-MS spectrum of pure 2-hydroxy-3-oxindole, acquired by GC-MS analysis after reaction of 2-TFE-3oxindole with water.
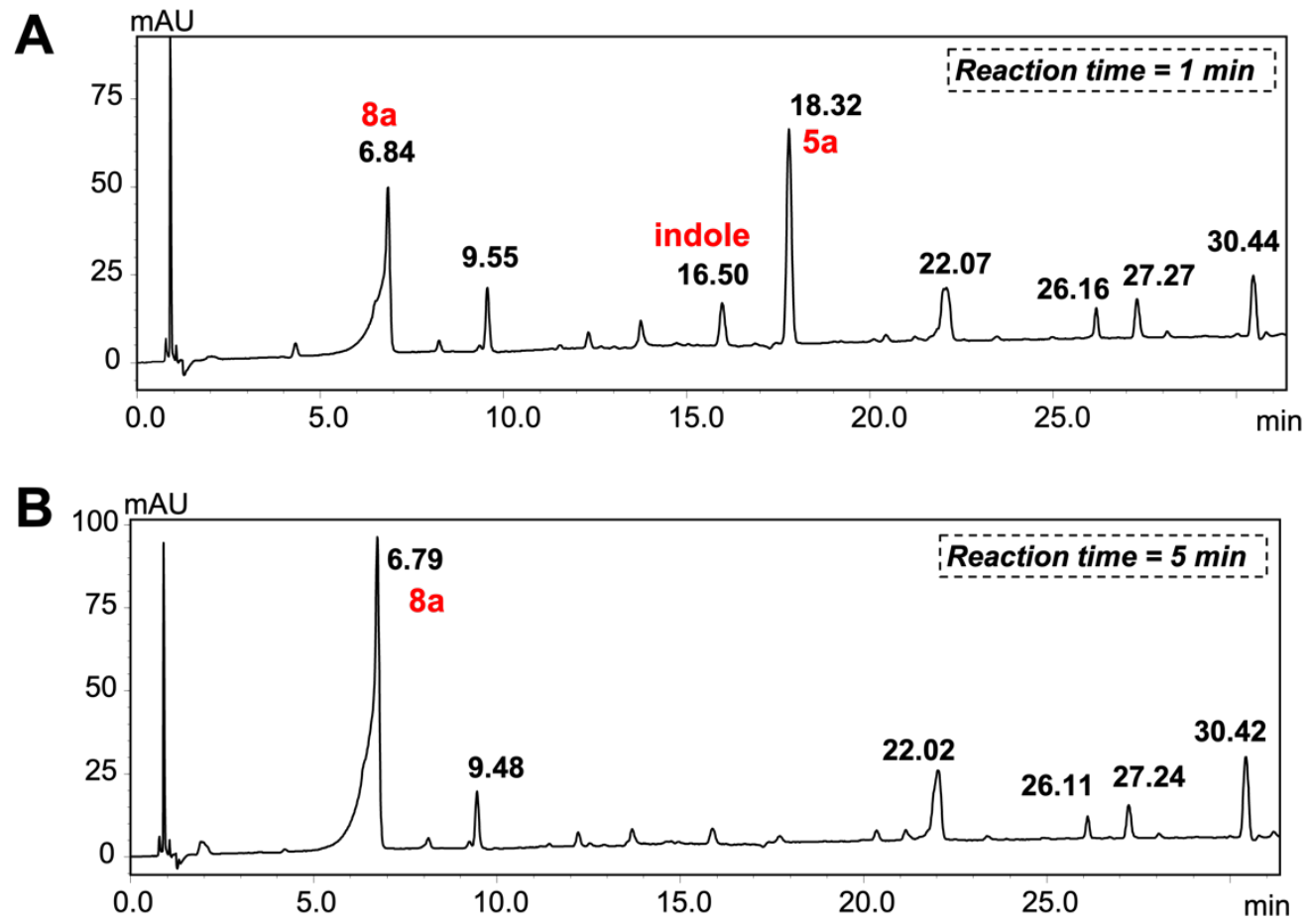

Figure S12. RP-HPLC chromatograms at $\lambda=240 \mathrm{~nm}$ of indole oxidation catalyzed by Mn-MC6*a at $\mathrm{pH} 10.5$ in the presence of TFE $(40 \% v / v)$. Traces collected after (A) 1 minute and (B) 5 minutes of reaction. Main products are labelled according to Scheme 3 (main text). 


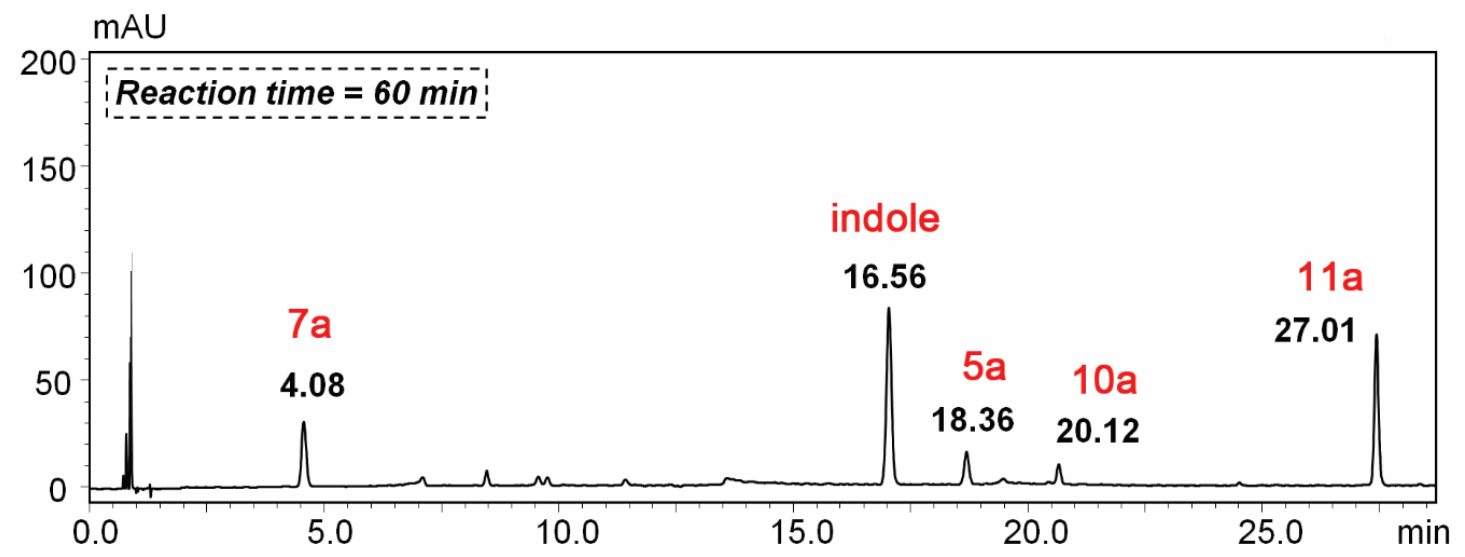

Figure S13: RP-HPLC chromatogram at $\lambda=240 \mathrm{~nm}$ of indole oxidation catalyzed by Mn-MC6*a at $\mathrm{pH} 6.5$ in the presence of TFE $(40 \% v / v)$. Traces acquired after 60 minutes of reaction. Identified products are labelled according to Scheme 3 (main text).
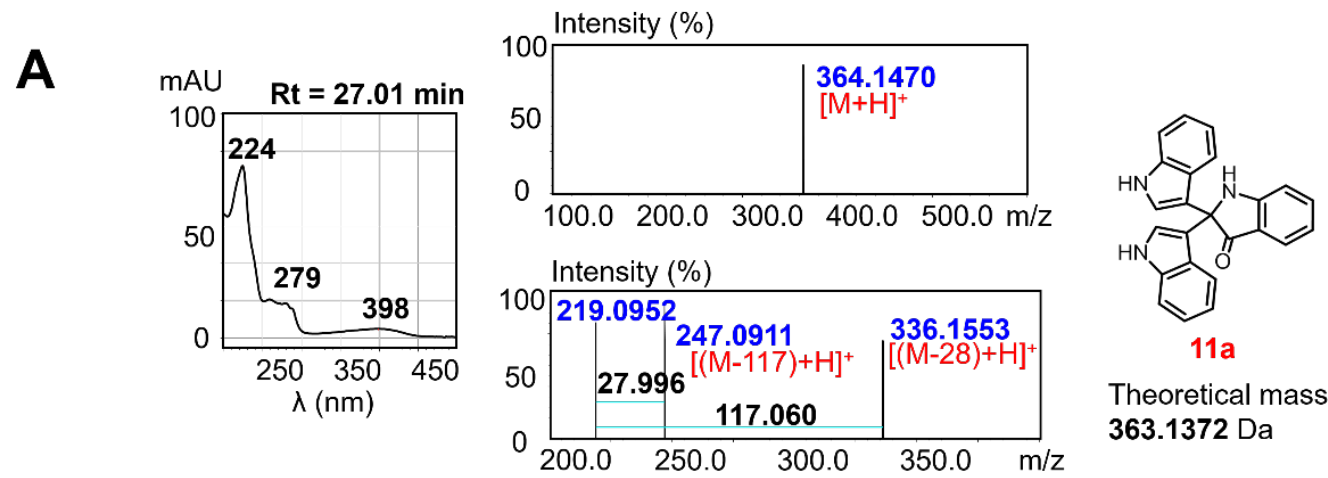

Theoretical mass:
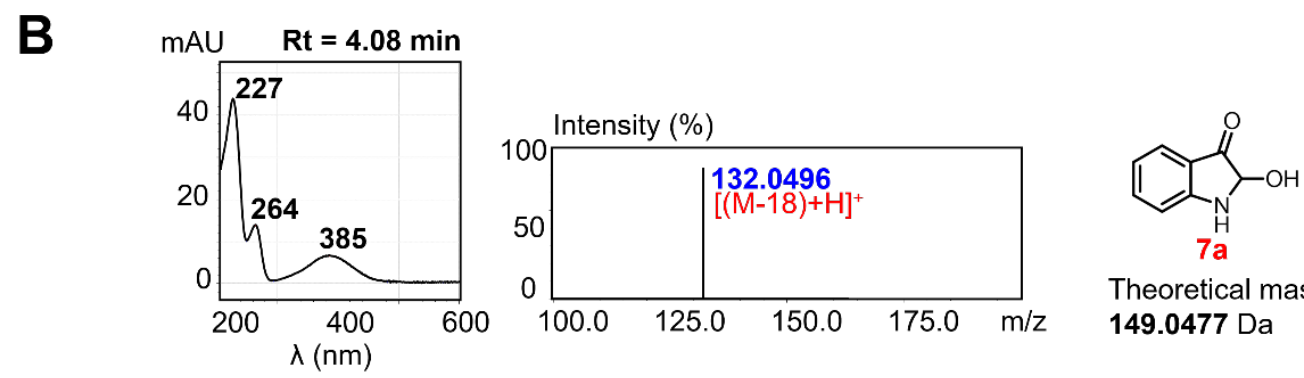

Theoretical mass:

C $\quad m A \cup \quad \mathbf{R t}=\mathbf{2 0 . 1 2} \mathbf{~}$ in
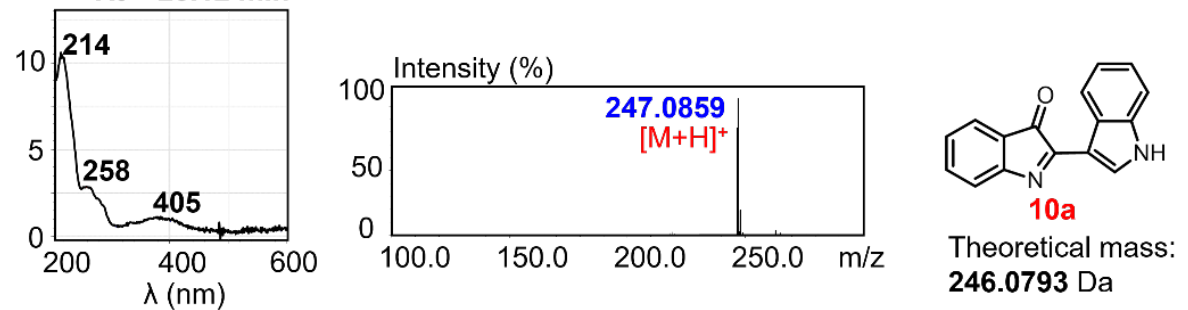

Figure S14. Experimental UV-Vis absorption spectra (left side) and high-resolution ESI-MS spectra (right side) of the products observed upon indole oxidation by Mn-MC6*a at $\mathrm{pH} 6.5$ in the presence of TFE (40\% v/v). (A) The product eluted at $27.01 \mathrm{~min}$ was identified with the pseudo-trimeric compound 2,2-bis(3'-indolyl)-3-oxoindole (11a), based on its HRMS spectrum (upper panel) and MS/MS fragmentation spectrum (lower panel) of the $[\mathrm{M}+\mathrm{H}]^{+}$ion $(\mathrm{m} / \mathrm{z}=364.1470$ Th). (B) The product eluted at 4.01 min was identified as 2-hydroxy-3-oxindole (7a). Elimination of $\mathrm{H}_{2} \mathrm{O}$ from 2-hydroxy3-oxindole likely occurs during MS analysis. (C) The product eluted at 20.12 min was identified as 2-(3-indolyl)-3oxindolenine (10a), resulting from the coupling of 3-hydroxy-indolenine and indole. Products are labelled according to Scheme 3 (main text). 
A

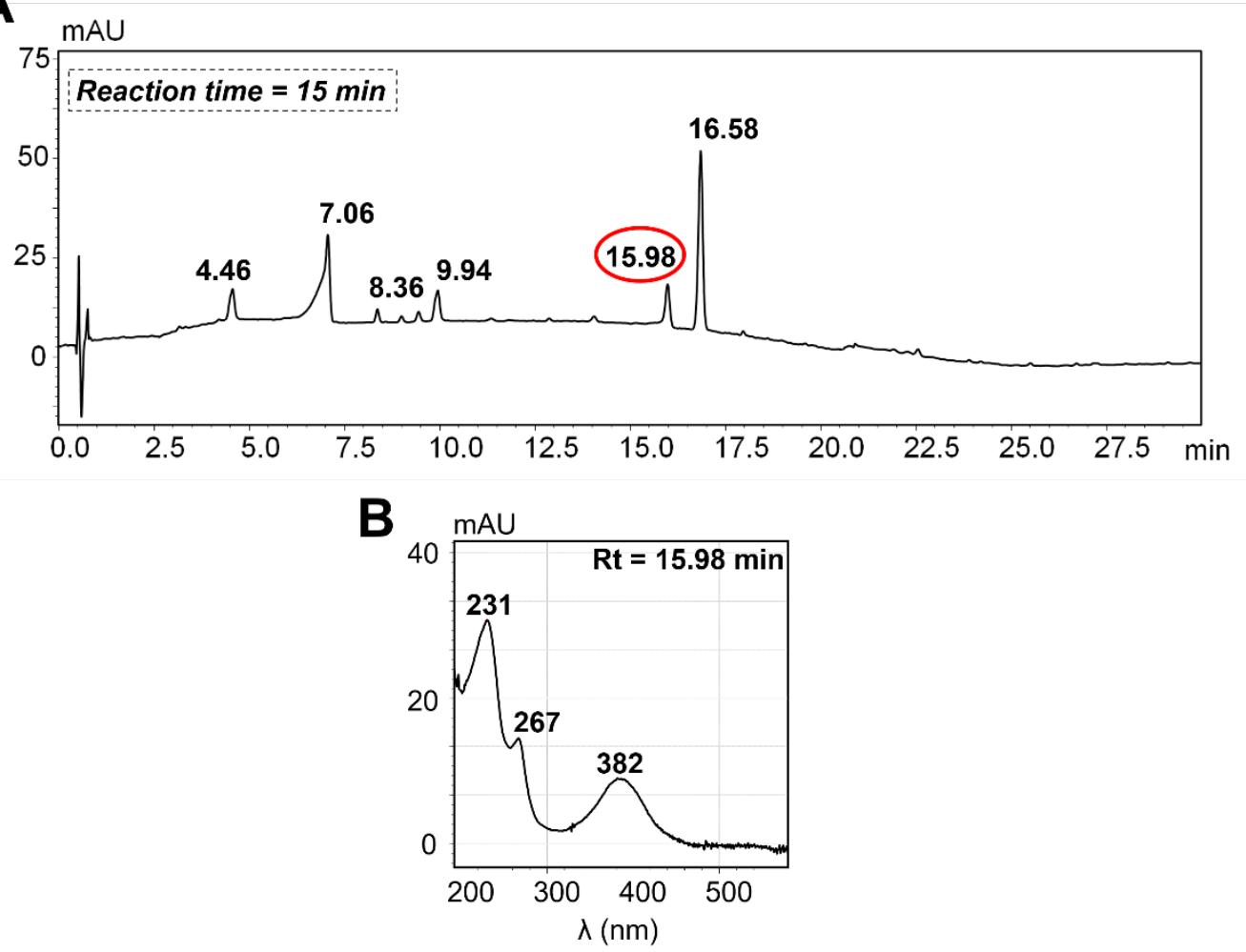

Figure S15. (A) RP-HPLC chromatogram at $\lambda=240 \mathrm{~nm}$ of indole oxidation catalyzed by Mn-MC6*a in $60 \mathrm{mM}$ sodium phosphate $\mathrm{pH} 8.5$ in the presence of methanol $(40 \% \mathrm{v} / \mathrm{v})$. (B) UV-Vis absorption profile of the product eluted at $\mathrm{Rt}=15.98 \mathrm{~min}$ and highlighted with a red circle. Analysis was performed after 15 minutes of reaction progress.

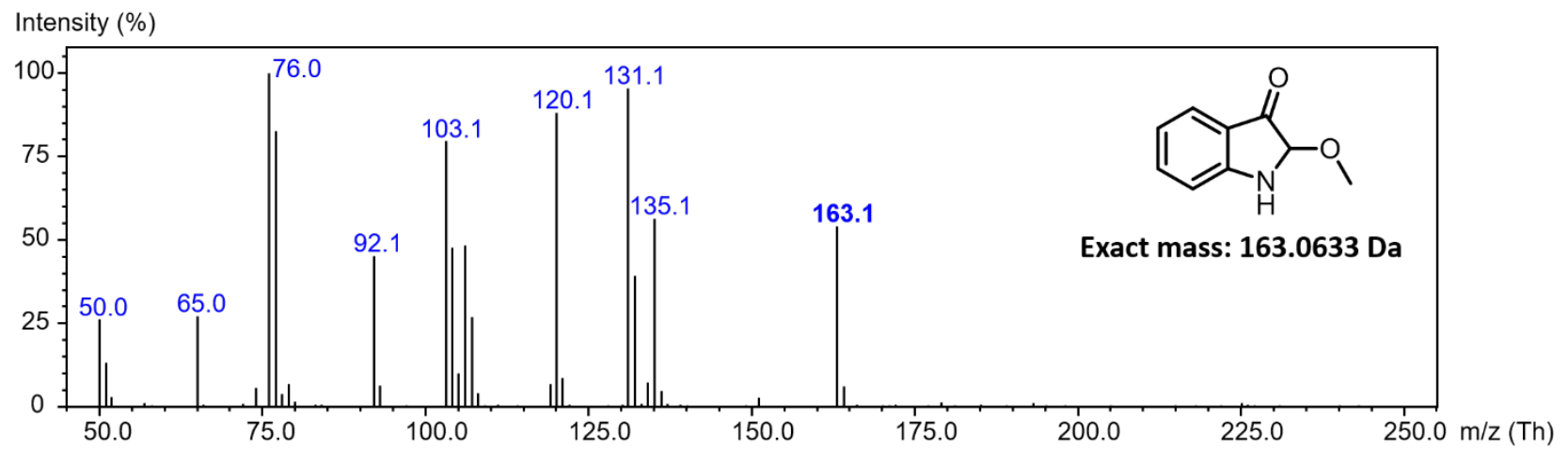

Figure S16. EI-MS spectrum of 2-methoxy-3-oxindole, detected upon Mn-MC6*a catalyzed indole oxidation in the presence of methanol $(40 \% v / v)$. The spectrum was collected upon GC-MS analysis of the extracted reaction mixture after 15 minutes. 
A
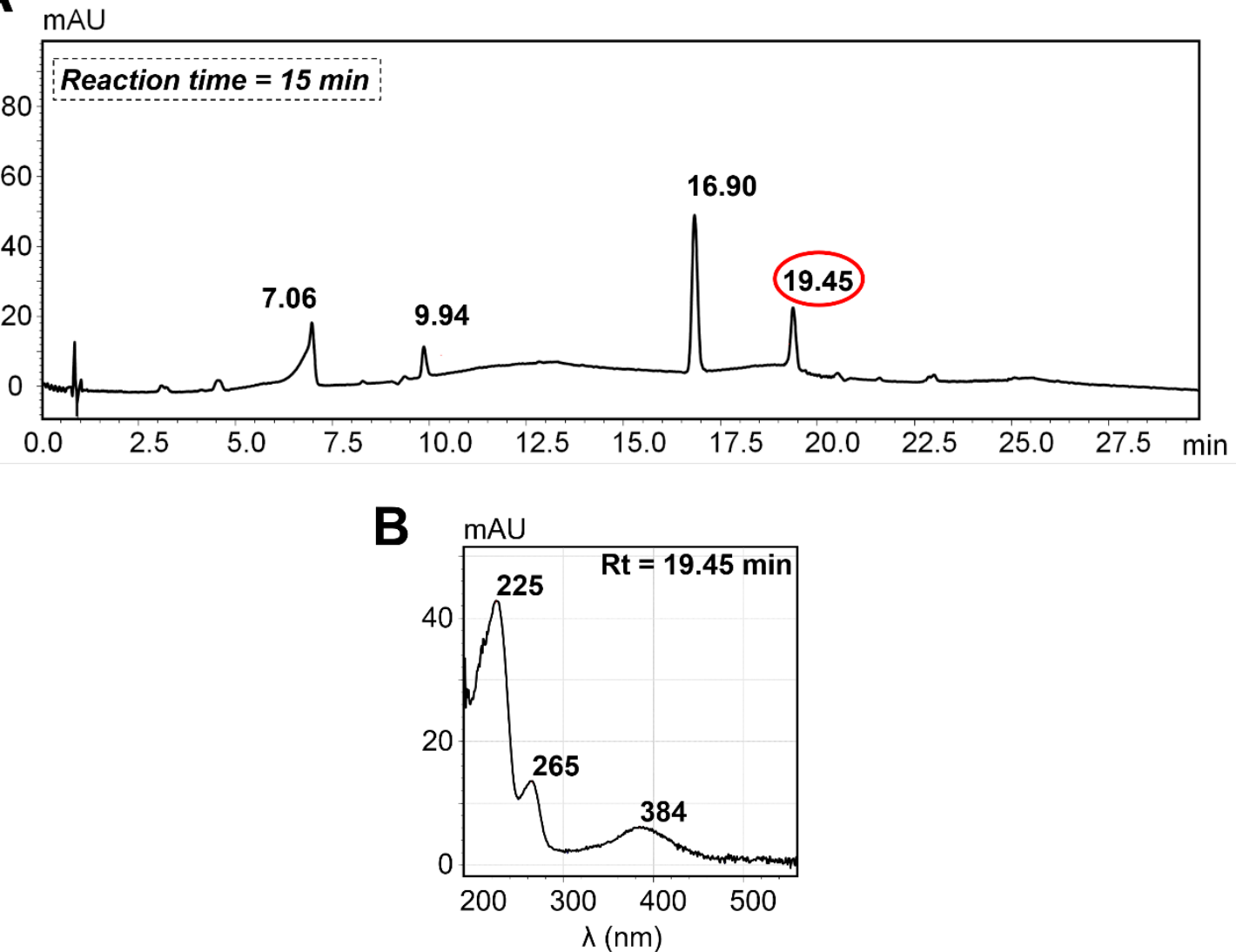

Figure S17. (A) RP-HPLC chromatogram at $\lambda=240 \mathrm{~nm}$ of indole oxidation catalyzed by Mn-MC6*a in $60 \mathrm{mM}$ sodium phosphate $\mathrm{pH} 8.5$ in the presence of ethanol $(40 \% \mathrm{v} / \mathrm{v})$. (B) UV-Vis absorption profile of the product eluted at $\mathrm{Rt}=19.45 \mathrm{~min}$ and highlighted with a red circle. Analysis was performed after 15 minutes of reaction progress.

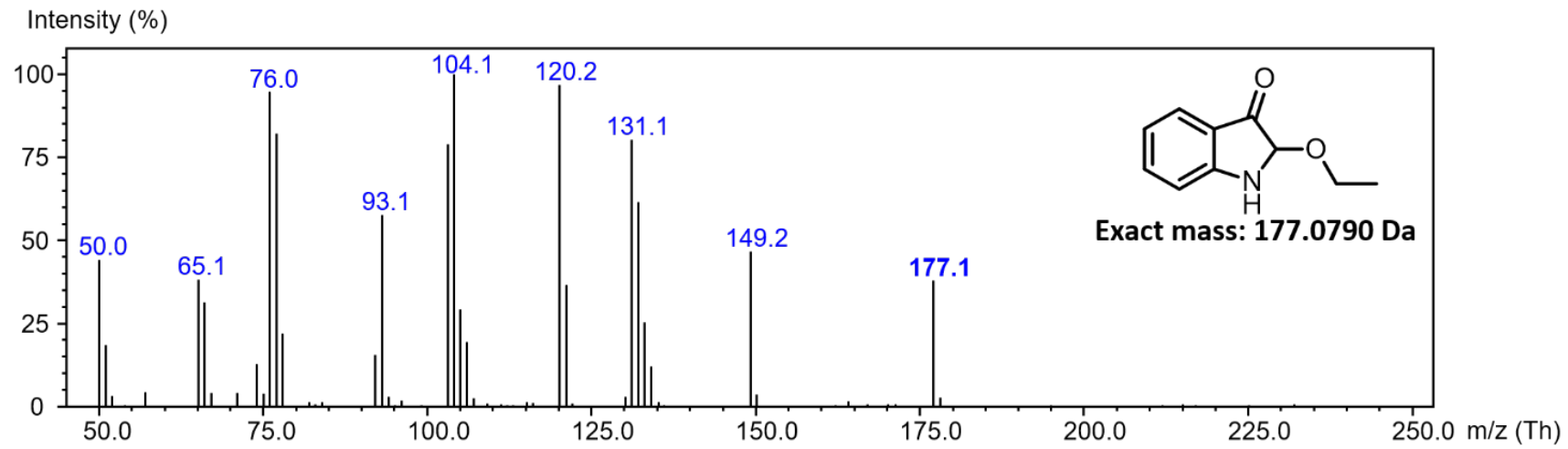

Figure S18. EI-MS spectrum of 2-ethoxy-3-oxindole, detected upon Mn-MC6*a catalyzed indole oxidation in the presence of ethanol $(40 \% \mathrm{v} / \mathrm{v})$. The spectrum was collected upon GC-MS analysis of the extracted reaction mixture after 15 minutes. 


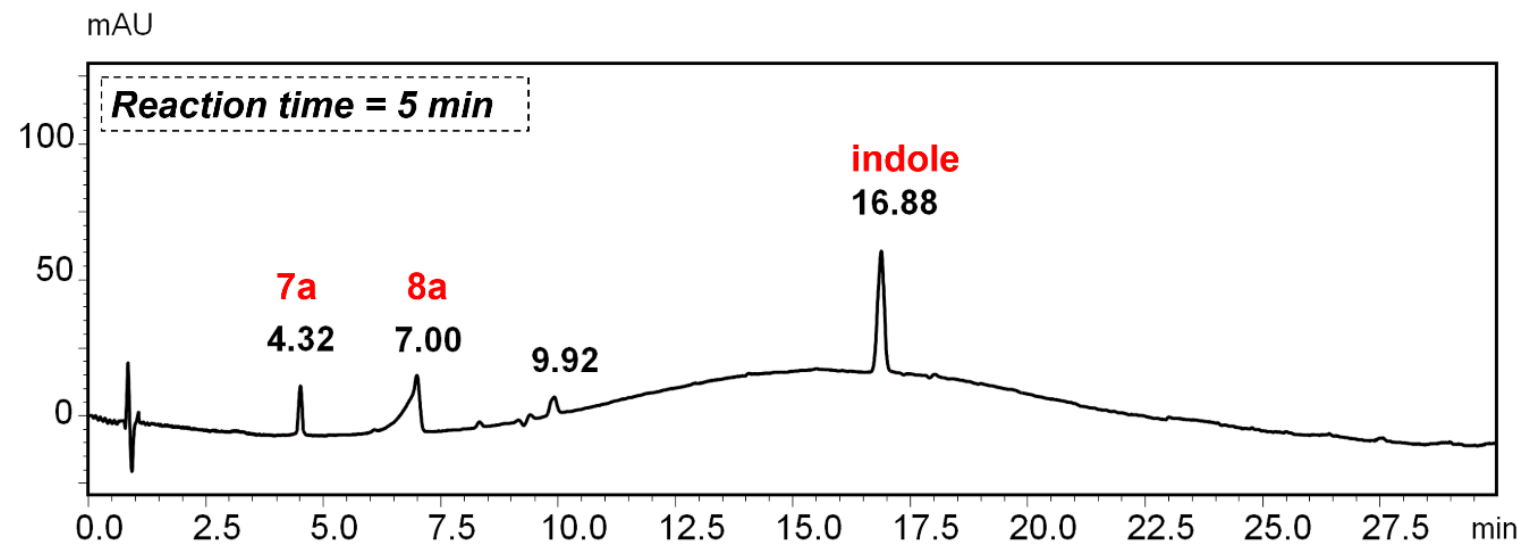

Figure S19. RP-HPLC chromatogram at $\lambda=240 \mathrm{~nm}$ of indole oxidation catalyzed by Mn-MC6*a in $60 \mathrm{mM}$ sodium phosphate $\mathrm{pH} 8.5$ in the absence of co-solvents. Products eluted at $\mathrm{Rt}=4.12 \mathrm{~min}$ and at $\mathrm{Rt}=7.00$ min correspond to 2 hydroxy-3-oxindole (7a) and isatin (8a). Identified products are labelled according to Scheme 3 (main text). Analysis was performed after 5 minutes of reaction progress.

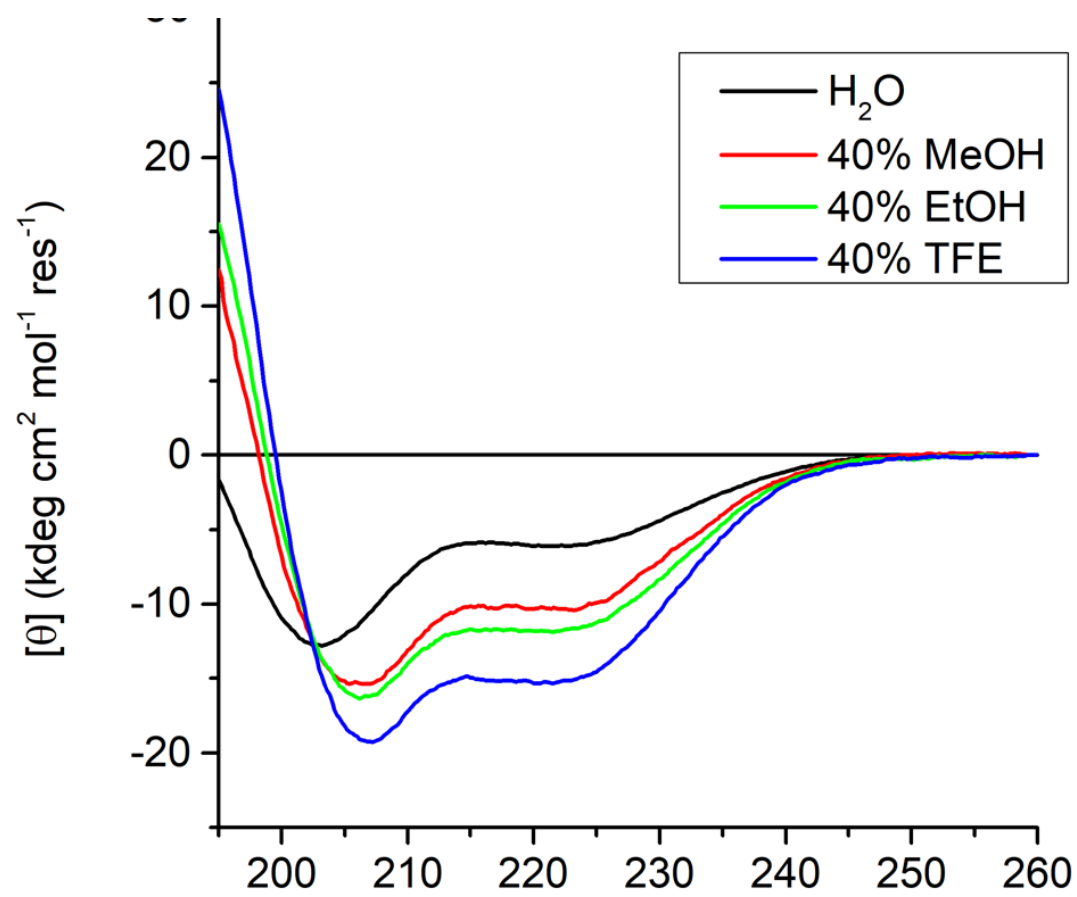

Figure S20. Superimposition of far UV region CD spectra of Mn-MC6*a (10 $\mu \mathrm{M})$ acquired in $5 \mathrm{mM}$ sodium phosphate $\mathrm{pH} 8.5$ in the absence (black trace) and in the presence of different co-solvents $(40 \% \mathrm{v} / \mathrm{v})$ : methanol (red line); ethanol (green line); TFE (blue line).

Table S2: Far-UV region CD parameters for Mn-MC6*a in aqueous solution at $\mathrm{pH} 8.5$ with different co-solvents $(40 \%$ $v / v)$.

\begin{tabular}{cccc}
\hline co-solvent & $\boldsymbol{\theta}_{\mathbf{2 2 2}}{ }^{[\mathbf{a}]}$ & $\boldsymbol{\theta}_{\mathbf{m i n}^{[\mathbf{a}, \mathbf{b}]}}\left(\boldsymbol{\lambda}_{\mathbf{m i n}}, \mathbf{n m}\right)$ & $\boldsymbol{\lambda}_{\mathbf{0}}{ }^{[\mathrm{c}]} \mathbf{n m}$ \\
\hline mone & -6.07 & $-12.7(202.6)$ & - \\
methanol & -10.3 & $-15.4(206.0)$ & 198.2 \\
ethanol & -11.8 & $-16.3(206.4)$ & 198.8 \\
TFE & -15.2 & $-19.3(207.2)$ & 199.5 \\
\hline
\end{tabular}

${ }^{[\mathrm{a}]} \theta$ is expressed as mean residue ellipticity $\left(\mathrm{kdeg} \mathrm{cm}^{2} \mathrm{dmol}^{-1} \mathrm{res}^{-1}\right) ;{ }^{[\mathrm{b}]}: \theta_{\min }$ represents the $\theta$ value at the shorter wavelength minimum (reported in parentheses); ${ }^{[c]}: \lambda_{0}$ represents the crossover wavelength. 


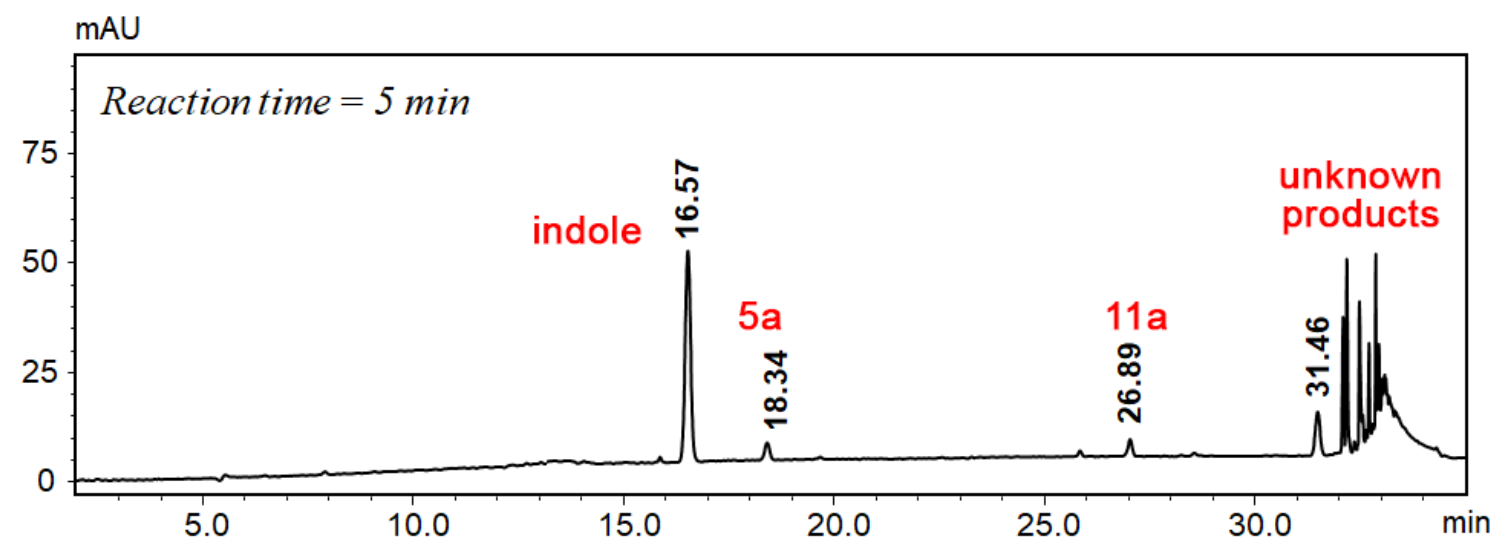

Figure S21. RP-HPLC chromatogram at $\lambda=240 \mathrm{~nm}$ of indole oxidation catalyzed by Mn-MC6*a in $60 \mathrm{mM}$ sodium phosphate $\mathrm{pH} 8.5$ in the presence of TFE $(40 \% v / v)$ and in the absence of $\mathrm{O}_{2}$. Identified products are labelled according to Scheme 3 (main text). Analysis was performed after 5 minutes of reaction progress. 


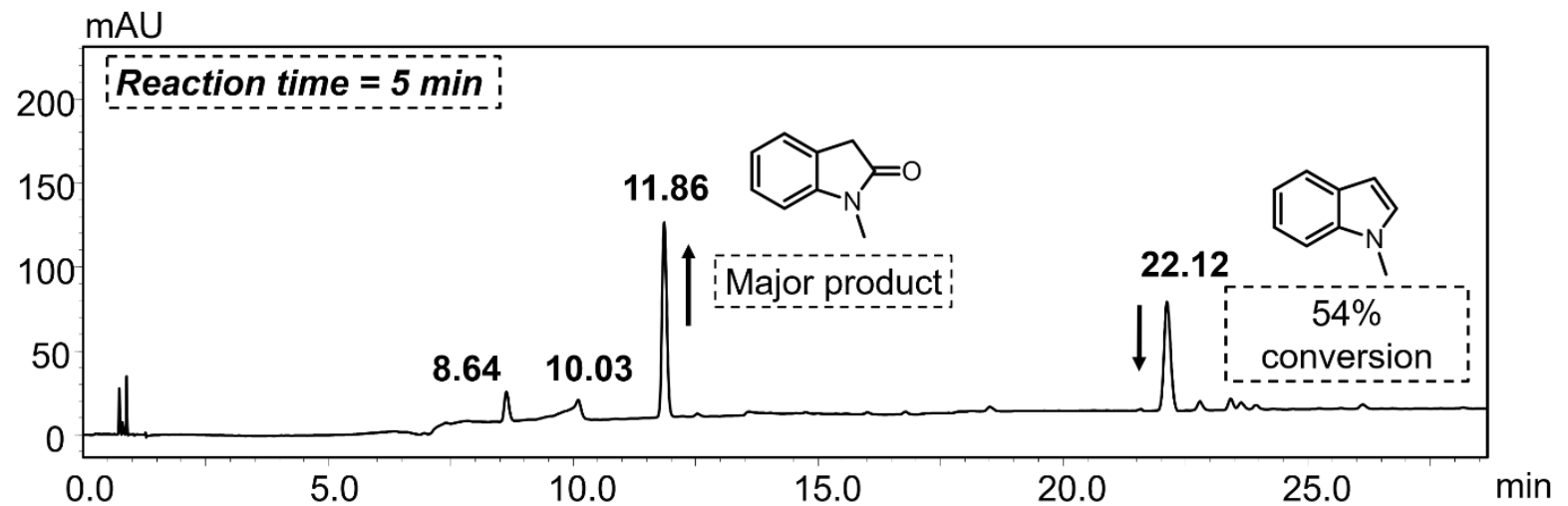

Figure S22. RP-HPLC chromatogram at $\lambda=240 \mathrm{~nm}$ of $N$-methyl-indole oxidation catalyzed by Mn-MC6*a at pH 8.5 in the presence of TFE $(40 \% v / v)$. Trace acquired after 5 minutes by the addition of the oxidant.
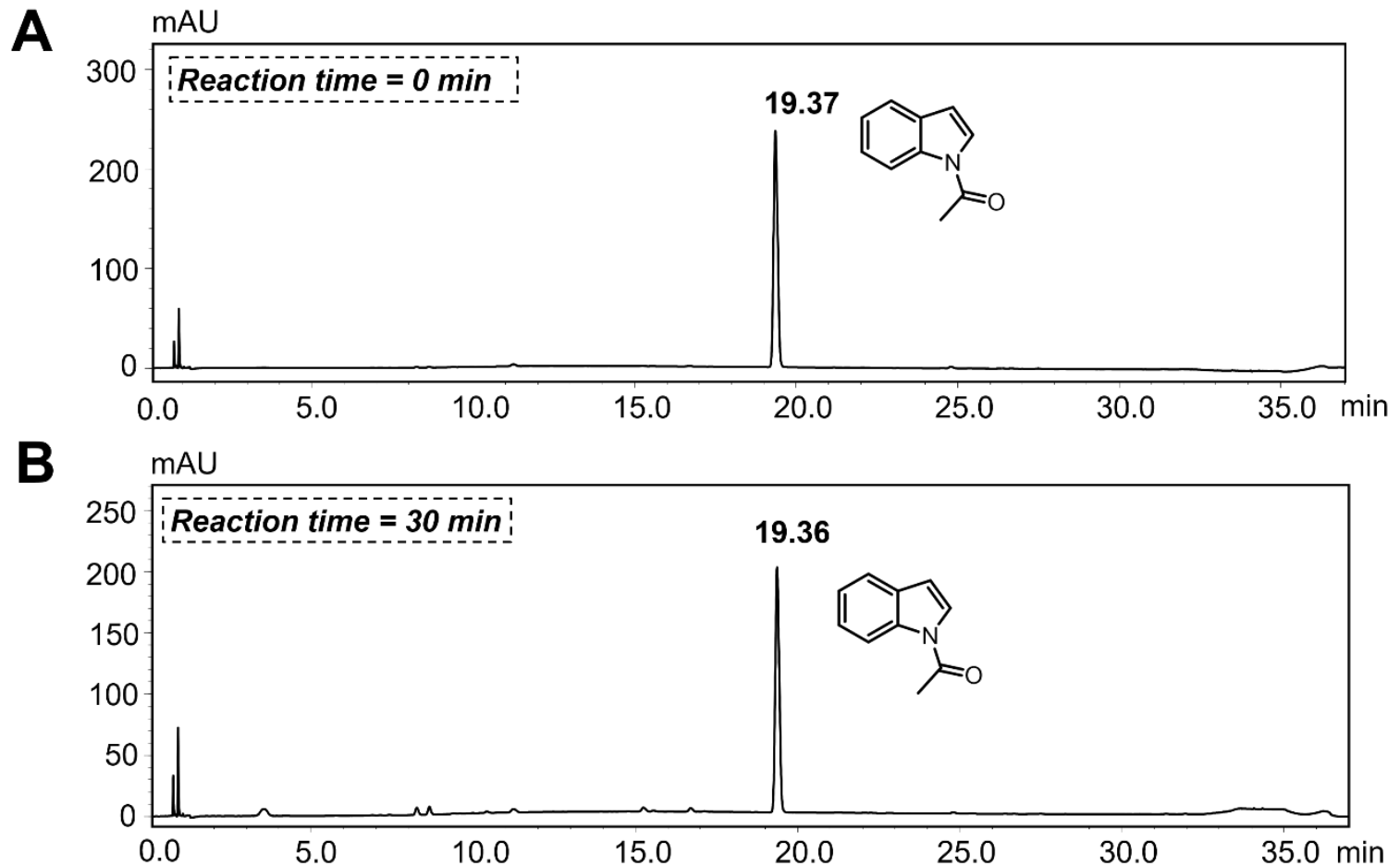

Figure S23: RP-HPLC chromatograms at $\lambda=240 \mathrm{~nm}$ of $N$-acetyl-indole oxidation in the presence of Mn-MC6*a and TFE $(40 \% v / v)$ at $\mathrm{pH} 8.5$. Traces acquired (A) before and (B) after 30 minutes by the addition of hydrogen peroxide. No significant substrate consumption was detected. 


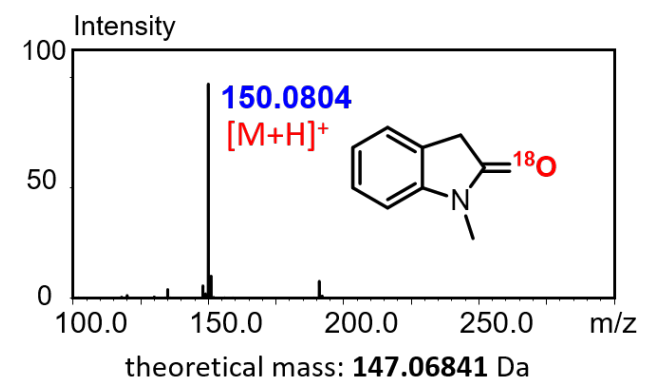

Figure S24. High resolution ESI-MS spectrum of $N$-methyl-2-oxindole, obtained when $\mathrm{H}_{2}{ }^{18} \mathrm{O}_{2}$ was used in the oxidation of $N$-methyl-oxindole catalyzed by Mn-MC6*a.
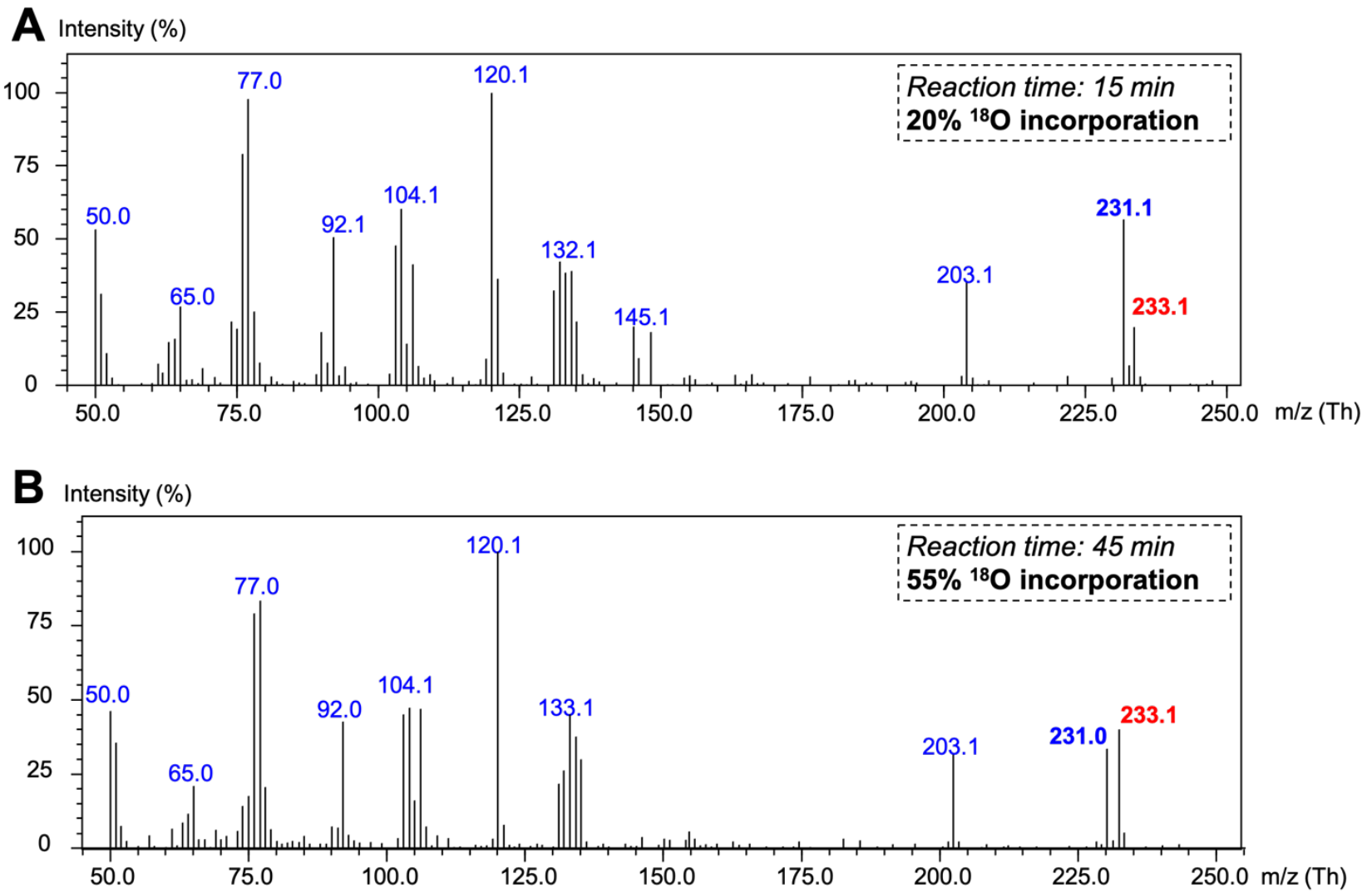

Figure S25. EI-MS spectra of 2-TFE-3-oxindole, acquired after (A) $15 \mathrm{~min}$ and (B) $45 \mathrm{~min}$ from treatment with labelled $\mathrm{H}_{2}{ }^{18} \mathrm{O}$ at $\mathrm{pH} 8.5$ and in the presence of TFE $(40 \% v / v)$. The spectra were collected upon GC-MS analysis of the reaction mixture extracted with ethyl acetate. 


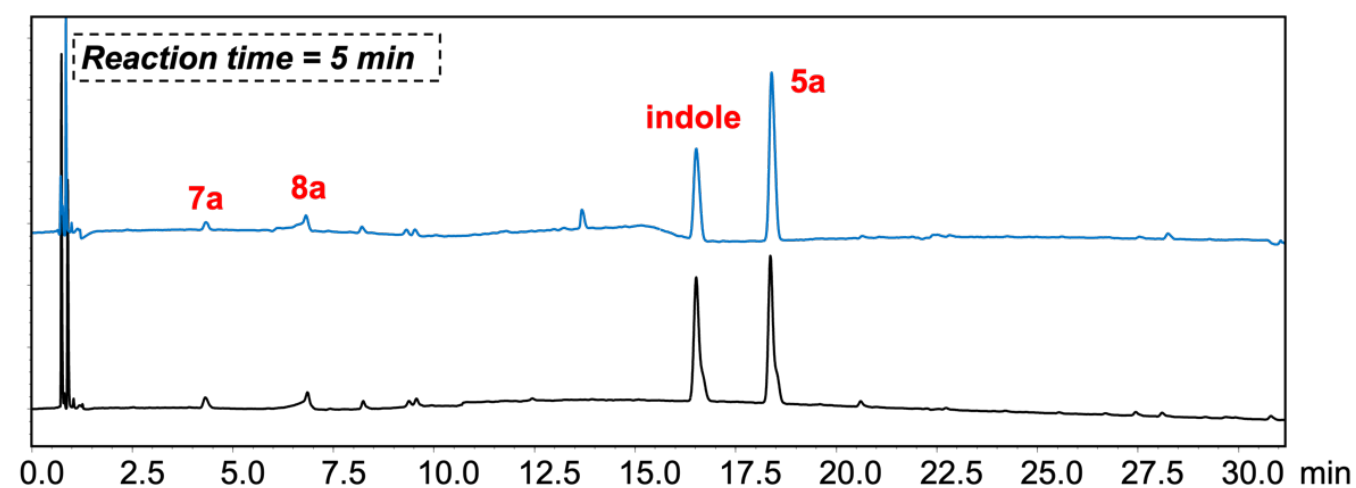

Figure S26. Comparison of the RP-HPLC chromatograms at $\lambda=240 \mathrm{~nm}$ of indole oxidation catalyzed by Mn-MC6*a at $\mathrm{pH} 8.5$ in the absence (black trace) and in the presence (blue trace) of D-mannitol as hydroxy radical scavenger. Analyses were performed after 5 minutes of reaction. Both reactions were performed in the presence of $40 \% v / v$ TFE. 

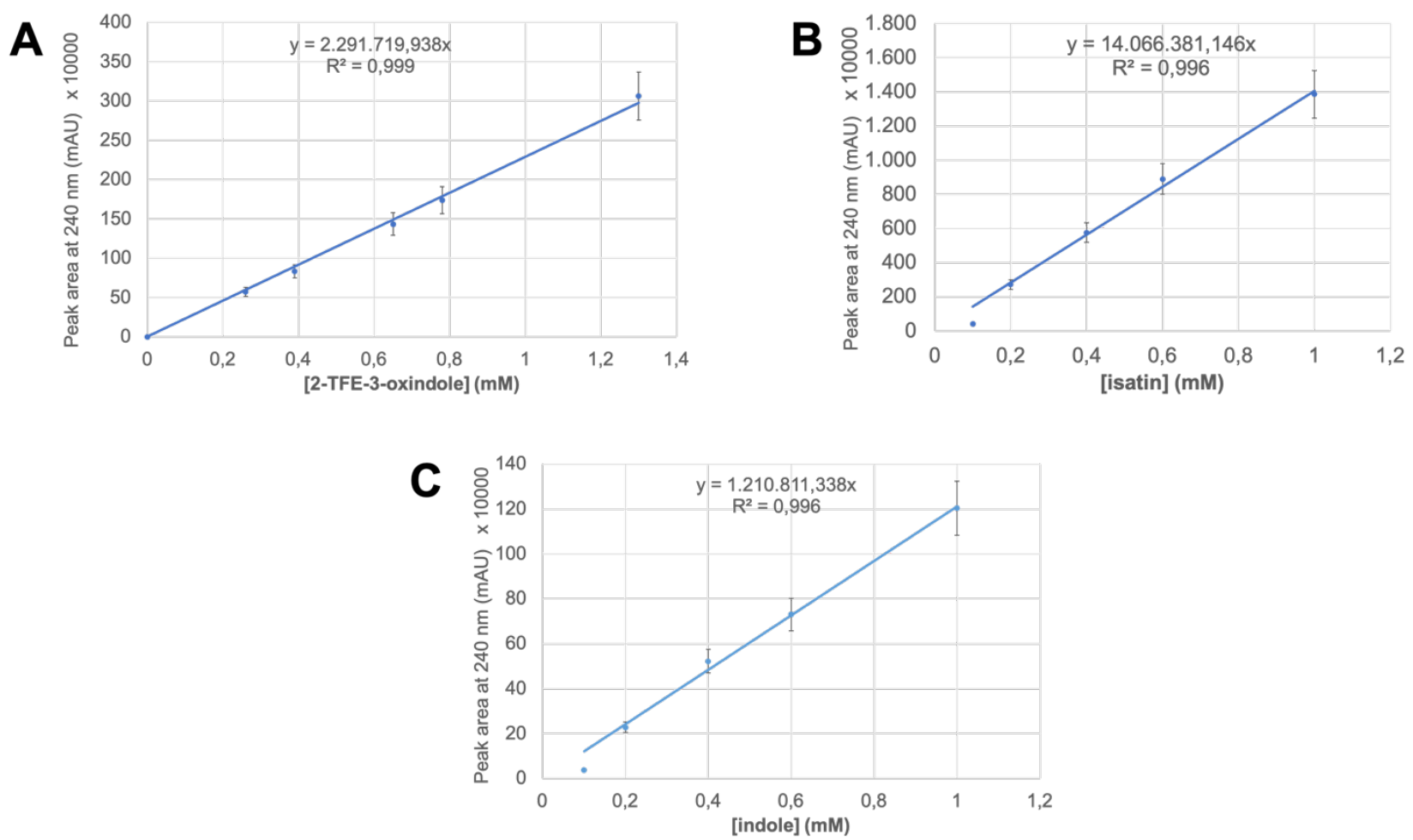

Figure S27. Calibration curves obtained by RP-HPLC analysis of solutions at known concentration of: (A) 2-TFE-3oxindole; (B) isatin; (C) indole. All solutions were prepared in acetonitrile and analyzed in the same chromatographic conditions used for the analyses of the reaction mixtures (see experimental section of the manuscript).

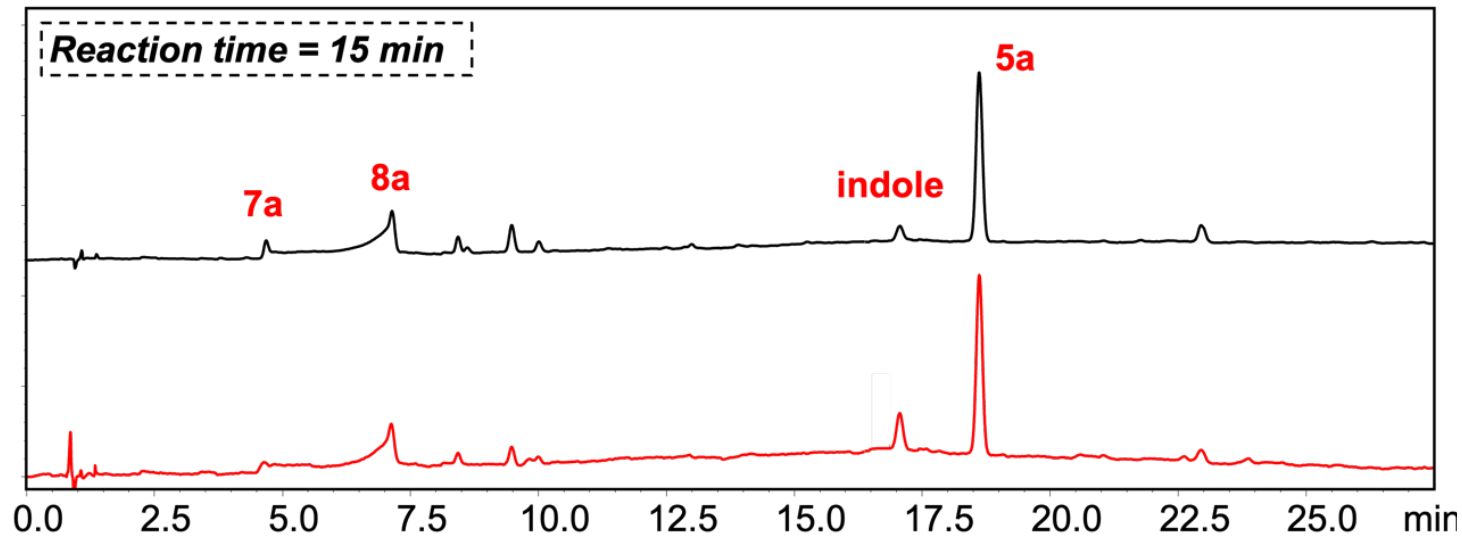

Figure S28. Superimposition of analytical RP-HPLC chromatograms at $\lambda=240 \mathrm{~nm}$ of indole oxidation catalyzed by MnMC6*a in the presence of TFE $(40 \% v / v)$ at $\mathrm{pH} 8.5$ before (red trace) and after (black trace) extraction with ethyl acetate and reconstitution in $\mathrm{H}_{2} \mathrm{O}$. The procedure for product purification is described in detail in the experimental section of the manuscript. 